\title{
Identification of shear zones and their causal mechanisms using a combination of cone penetration tests and seismic data in the Eastern Niger delta
}

\author{
Garziglia $S^{1}$, Sultan $N^{1}$, Cattaneo $A^{1}, \operatorname{Ker} S^{1}$, Marsset $B^{1}$, Riboulot $V^{1}$, Voisset. $M^{1}$, \\ Adamy $\mathrm{J}^{2}$, Unterseh $\mathrm{S}^{2}$
}

\author{
1 IFREMER, BP 70, 29280 Plouzané Cedex, France \\ 2 TOTAL, Paris La Défense France
}

\begin{abstract}
:
In a site investigation of the eastern part of the offshore Niger delta, cone penetration tests (CPTU) showed significant drops in tip resistance, associated with decreases in sleeve friction and induced excess pore pressures at the interface between superficial sediments and the underlying deposits of a mass-transport complex (MTC) called NG1. Such signature characteristics of weakened zones are clearly expressed at three sites where the drop in tip resistance reaches more than $40 \%$ over $2-3 \mathrm{~m}$-thick intervals. Correlations between CPTU profiles and both 3D and ultrahigh-resolution 2D seismic data suggest that the weakened zones surround syndepositional the within the frontal part of NG1. Hence, weakening appears associated with the remobilization of thrust faults, inducing localized plastic shear. Relatively recent, deep-seated structural movements affecting NG1 are suspected to have remobilized these thrusts faults. When considering the sole influence of gravity, the fact that shear strength is mobilized within scattered, limited zones along steeply dipping syndepositional faults is not favorable for the further development of a continuous slope-parallel failure surface above NG1.
\end{abstract}

Keywords: Cone penetration tests ; shear zone ; 3D seismic ; ultrahigh-resolution 2D Seismic ; mass transport complex; slope stability

\section{Introduction}

The Niger delta has prograded since the early Tertiary onto the oceanic crust of the Gulf of Guinea to form one of the world's largest modern delta systems. It has a distinctive structural zonation resulting from largescale gliding and spreading (Hooper et al., 2002). Early to middle Tertiary overpressured shales provide regional detachment levels that link updip extension, downdip contraction and compensating translation of the intervening overburden. Superimposed on the primary accommodation created by these structural movements, compensation is provided by depositional processes (Hooper et al., 2002). Submarine slope failures and related products can induce both destructive and constructive compensation (Hooper et al., 2002).

In the frame of a collaboration project between IFREMER and TOTAL, the ERIG3D cruise was conducted in 2008 to study slope failure processes in the eastern part of the Niger delta. A large-scale buried masstransport complex (MTC), initially identified on 3D seismic data and called NG1 (Fig.1), was targeted for a thorough investigation using multidisciplinary methods. In this paper, special attention is paid to weakened zones that were identified in the upper part of NG1 using in situ geotechnical measurements. While slope failure often develops within weakened zones (Leroueil 2001, Urciuoli et al., 2007), geophysical, sedimentological and geotechnical data were combined to unravel the origin and the geometry of the weakened zones as a key to assess the presentday slope stability in the area. 


\section{Materials and methods}

\subsection{Geophysical analysis}

The 3D seismic volume used in this study was short-offset processed and pre-stack time migrated to enhance the resolution in the shallow part (Fig.1b). The inline spacing is $6.25 \mathrm{~m}$, and the crossline spacing is $12.5 \mathrm{~m}$. The vertical and horizontal resolutions are approximately 7 and $15 \mathrm{~m}$ respectively. Seismic interpretation and attribute analyses were done using the Sismage software developed by TOTAL.

Ultrahigh-resolution (UHR) seismic lines were acquired during the ERIG3D cruise using a new deep-sea sub-bottom profiler developed by IXSEA and IFREMER (Le Gall et al., 2008). It consists of a single light transducer working in the 1.8-6.2 kHz frequency band and a three hydrophones array as a receiver. This system was mounted on an autonomous underwater vehicle (AUV) to acquire 16 seismic lines (43 km) at constant altitude $(80 \mathrm{~m})$ with a shot spacing of $1.8 \mathrm{~m}$ (Fig. 1c). The vertical resolution is close to $20 \mathrm{~cm}$.

\subsection{Core analysis}

The $21.4 \mathrm{~m}$ long Calypso piston-core ER-CS09 was recovered to reach the upper part of NG1 (Fig. 1c). Before splitting, the bulk density was measured using a GEOTEK multisensor core logger (MSCL, www.geotek.co.uk). Analyses on split sections included lithological descriptions, water content determination, undrained shear strength measurements (vane shear test) and P-wave velocity measurements (celerimeter, see Sultan et al., 2008). The Atterberg consistency limits were determined using the fall cone method described by Koumoto and Houlsby (2001). Compressibility tests using an oedometer with incremental loading were carried out on 4 samples (see Fig. 4).

\subsection{In situ measurements}

In situ measurements were carried out using the Penfeld penetrometer with both a standard piezocone (CPTu) and a sonic fork (for more details see Sultan et al., 2007). With the standard piezocone, continuous measurements of the tip resistance $\left(q_{\mathrm{c}}\right)$, sleeve friction $\left(f_{s}\right)$ and induced excess pore pressure $\left(\Delta u_{2}\right)$ were performed at 14 sites down to 30 m below seabed (mbsb) (Fig. 1c). The measured excess pore pressure $\left(\Delta u_{2}\right)$ was used to calculate the corrected tip resistance $\left(q_{\mathrm{t}}\right)$.

At 5 sites, in-situ P-wave velocity $\left(V_{\mathrm{p}}\right)$ measurements were performed down to $30 \mathrm{mbsb}$ using the sonic fork (Fig. 1c). These were used to relate time to depth in order to accurately correlate sedimentological, geotechnical and geophysical data.

\section{Results}

\subsection{Morphostructure of the study area}

Extending from the shelf edge at $\sim 200 \mathrm{~m}$ below sea level (mbsl) to the mid-slope at 900 mbsl, the study area shows a morphology controlled by structural movements (Fig. 1). Normal growth faults occur on the upper slope where an arcuate escarpment suggests relatively recent activity (Fig. 1). Downslope, two shale-cored anticlines form dome-shaped bathymetric highs. The most prominent one, referred to here as the midslope bathymetric high (MSBH), culminates at $~ 50 \mathrm{~m}$ above the surrounding seabed. On its NW flank, seabed undulations show crests orientated perpendicular to the maximum 
slope (Fig. 1). Whether these features result from sediment deformations, deposition or a combination of both is as yet unclear. In the same sector, the seabed topography is also affected by collapse normal faults related to the growth of the underlying shalecored anticline (Fig. 1b \& c). Oval depressions interpreted as pockmarks affect a large portion of the seabed (Fig. 1). Some of them are clearly aligned along collapse normal faults surrounding the shale-cored anticlines. Other pockmarks seem related to buried sedimentary bodies (Fig. 1).

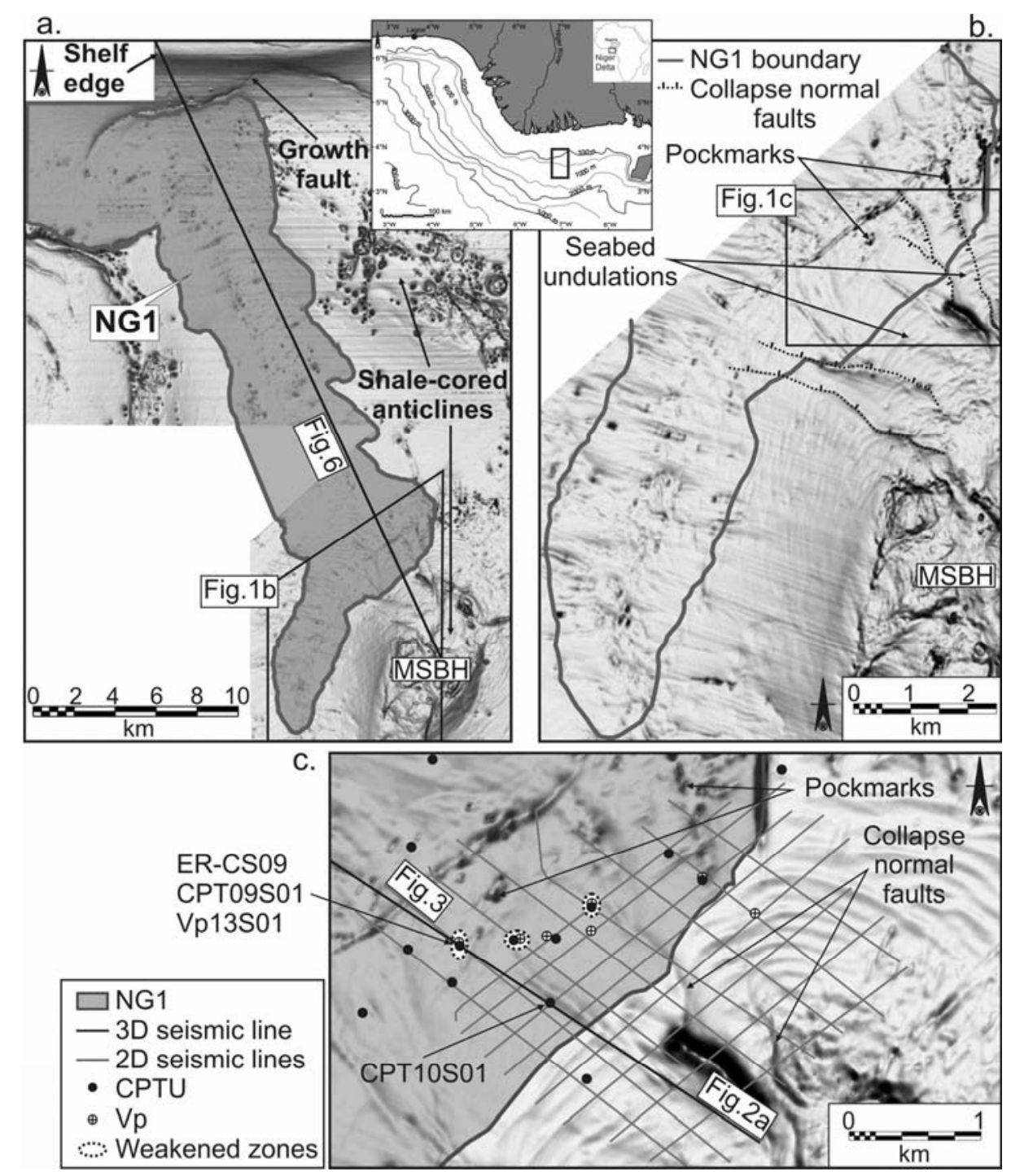

Figure 1. a) Seabed dip map from three 3D seismic volumes showing the main deformational structures surrounding the MTC NG1 whose areal extension is indicated in grey. (MSBH: mid-slope bathymetric high). b) Dip map showing the main seabed features above the distal part of NG1 bounded by the dark grey line. c) Seabed dip map showing the location of the data acquired during the ERIG3D cruise. Location of the seismic lines, core and CPTu profiles presented in Figs 2, 3, 4 and 5 are identified. 


\subsection{Seismic analysis of the MTC NG1}

The MTC NG1 was identified on 3D seismic data using criteria established from previous studies (Frey-Martinez et al., 2006 and references therein). Mapping of its upper and lower bounding surfaces reveals that it covers, at least, an area of $\sim 200 \mathrm{~km}^{2}$ for an estimated volume of $\sim 12 \mathrm{~km}^{3}$ (Fig. 1a). These values are underestimates since the continuation of NG1 beyond the NW border of the 3D seismic dataset could not be mapped. The areal extent of NG1 roughly presents a boot shape, with the heel resting at the base of the MSBH (Fig. 1). The most proximal deposits of NG1 identified, lie on the upper slope at $\sim 300 \mathrm{mbsl}$. (Fig. 1a). The upslope part of NG1 is affected by the arcuate growth faults (Fig. 1a). Its toe rests at mid-slope at $\sim 900$ mbsl. The thickness of the sediment overlying NG1 is up to $120 \mathrm{~m}$ on the upper slope and decreases progressively to $\sim 15-30 \mathrm{~m}$ at mid-slope. Based on the combined analyses of its architectural geometry and deformational structures, NG1 is a composite feature preserving multiple genetically related mass-wasting events.

The present study focuses on the distal part of NG1, between 700 and 900 mbsl, where the thickness of its overburden does not exceed the maximum penetration depth of the corer and the penetrometer (i.e. $30 \mathrm{mbsb}$ ) (Fig. 1b). In this area, the pathway of NG1 appears to have been deflected towards the SW by the MSBH (Fig. 1). While the eastern edge of NG1 rests on the flank of the MSBH dipping at $1-3^{\circ}$ to the NW (Fig. 2a), the bulk of its deposits spread along a gentle $\left(\leq 1^{\circ}\right)$ south-westwards dipping slope.

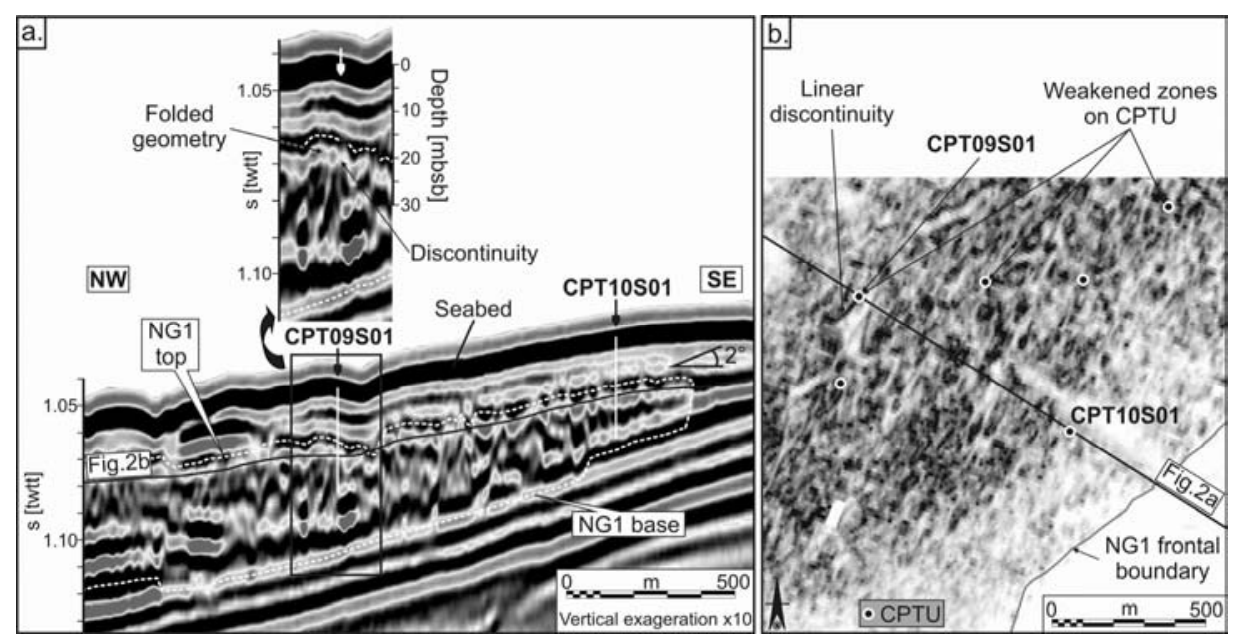

Figure 2. a) Below: 3D seismic line across the frontal part of the MTC NG1 on the flank of the MSBH (location shown in Figs. 1c and 2b). The location of the coherency slice presented in Fig. 2b is indicated by a black line cross-cutting the upper part of NG1. Above: Close-up of a folded geometry on the top of NG1 discussed in the text. The white arrow indicates the location of the CPT09S01. b) Coherency slice cross cutting the upper part of NG1 (position of slice shown in Fig. 2a). Zones of lower coherency appear in darker tones. The circles show location of the CPTu measurements. Note that the location of the CPT09S01, where a weakened zone is clearly expressed, ties to a linear discontinuity.

On 3D seismic lines, NG1 is generally characterized by internal chaotic reflections of low amplitude overlaid by reflections of higher amplitude and continuity which form a hummocky top with gentle topographic relief (Fig. 2a). The higher relief on the top of NG1 correlate to folded geometries generally adjacent to steeply dipping discontinuities $\left(\sim 35^{\circ}\right)$ (Fig. 2a). In planform, such as observed on a coherency slice cross-cutting the upper part of NG1, the most prominent of these discontinuities appear as lineations oriented perpendicular to the slope direction (Fig. 2b). The base of NG1 shows a highly irregular surface cross-cutting stratigraphy (Fig. 2a). 
On 2D seismic data, NG1 appears as a transparent body underlain by a continuous, high amplitude reflector (Fig. 3). It is generally bounded above by hyperbolic reflections and high amplitude patches ascribed to the blocky nature of its top surface. However, in some places, the top of NG1 is only faintly discernible or even invisible (Fig.3). On the flank of the MSBH, the frontal part of NG1 is buttressed against continuous reflections of undeformed strata (Fig. 3).

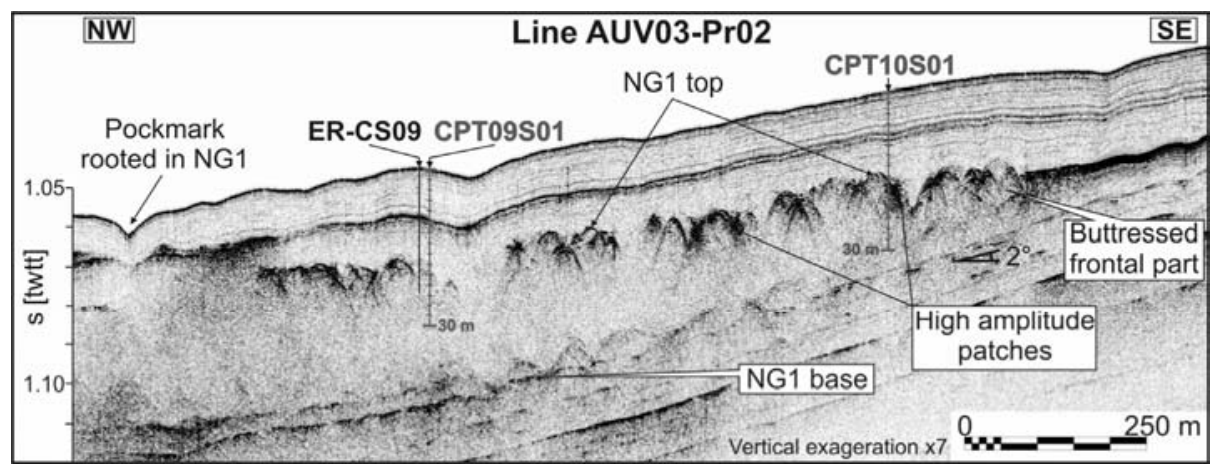

Figure 3. Ultrahigh-resolution seismic line acquired with the AUV across the frontal part of the MTC NG1 on the flank of the MSBH (location shown in Fig. 1c). Location of core ER-CS09, CPT09S01 and CPT10S01 shown in Figs. 4 and 5 are identified.

\subsection{Sediment core analyses}

The core ER-CS09 was collected at a site where only faint hyperbolic reflections enable to identify the top of NG1 on 2D seismic data (Fig. 3). The ER-CS09 lithology is dominated by dark silty clay (Fig. 4). At 7 and $17 \mathrm{~m}$, two silt layers are clearly marked by a decrease in water content and an increase in bulk density (Fig. 4).

Deformational structures are only observed at the base of core ER-CS09 (19.76-20.76 $\mathrm{m}$ ) in an interval containing tilted bedding and small-offset faults (Fig. 4). The top of NG1 deposits is not visually discernable. Based on the correlation between laboratory and in situ $V_{\mathrm{p}}$ measurements which were tied to 2D seismic data, the top of NG1 should be located at $17.2 \mathrm{~m}$ in the core, just below a silt layer (Fig. 4). Below this depth, the water content is between 6 to $14 \%$ higher than the decreasing trend of the overlying sediment represented by the grey curve in Fig. 4 . This observation coincides with a density profile with values between 1.48 and 1.39, which are between 6 and $12 \%$ lower than the grey line representing the trend of the overlying sediments (Fig. 4). These changes in water content and bulk density trends are interpreted to reflect the transition from undeformed sediments above to NG1 deposits below.

The plastic limit $\left(W_{\mathrm{P}}\right)$ is quasi-constant within the core, in the range $52 \%{ }^{+} / .5 \%$, while the liquid limit $\left(W_{\mathrm{L}}\right)$ is slightly more variable, ranging from 118 to $136 \%$ (Fig. 4). The plasticity index $\left(I_{\mathrm{P}}\right)$ varies between 69 and $84 \%$. The liquidity index $\left(\mathrm{L}_{\mathrm{L}}\right)$ decreases with depth from 0.88 at $6.2 \mathrm{~m}$ to 0.61 at $20.5 \mathrm{~m}$ (Fig. 4). None of the index properties show any significant change between undeformed sediments and NG1 deposits.

The transition at $17.2 \mathrm{~m}$ is also not clearly marked on the shear strength $(\mathrm{Su})$ profile which is quasi-linear from the top to the base of core ER-CS09 (Fig. 4). Consolidation tests indicate that the 4 tested samples are normally consolidated (i.e. $0.94<\mathrm{OCR}<1.07$ ) (Fig. 4). The ratio of undrained shear strength to vertical effective stress $\left(\mathrm{Su} / \sigma^{\prime}{ }_{v 0}\right)$ is estimated to 0.325 for normally consolidated sediments. From the grey line representing this theoretical ratio on the strength profile in Fig. 4, the upper part of NG1 is normally consolidated. 


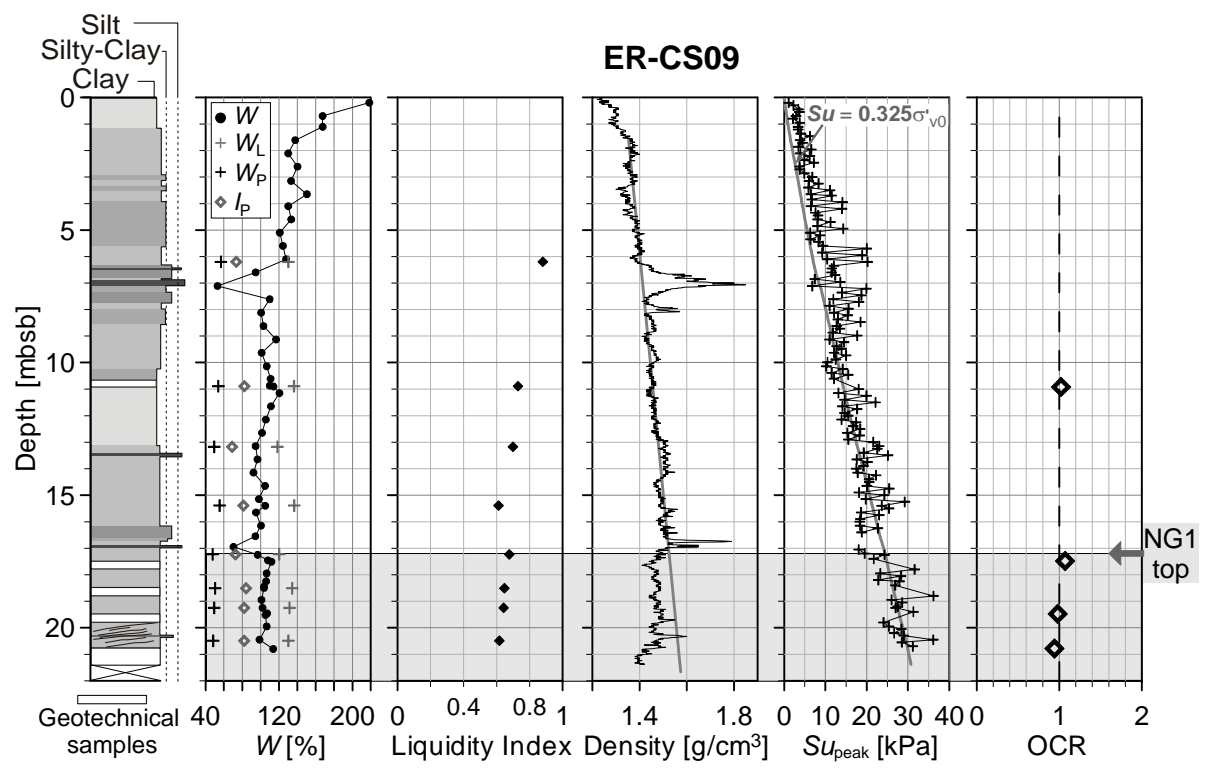

Figure 4. Lithological and geotechnical logs of core ER-CS09 (location shown on Fig. 1) (W: water content, $W_{\mathrm{L}}$ : liquid limit, $W_{\mathrm{P}}$ : plastic limit, $I_{\mathrm{P}}$ : Plasticity Index, Density from MSCL, $S u_{\text {peak }}$ : Undrained vane shear strength, OCR: overconsolidation ratio from oedometer tests on 4 samples).

\subsection{In situ analyses}

Two distinct units are identified on the 12 CPTu profiles performed in the area of NG1. The upper unit is characterised by a quasi-linear increase of the corrected tip resistance $\left(q_{t}\right)$, the sleeve friction $\left(f_{s}\right)$ and the induced excess pore pressure $\left(\Delta u_{2}\right)$ from the seabed down to $\sim 18-20$ mbsb (Fig. 5). By analogy with core analyses, the upper unit consists primarily of clay-rich sediments. In the lower unit, $q_{\mathrm{t}}, f_{\mathrm{s}}$ and $\Delta u_{2}$ show irregular profiles, with higher values than those of the upper unit (Fig. 5). These characteristics reflecting the chaotic internal nature of NG1 suggest that, during its emplacement, stress and strain were partitioned in a complicated fashion, varying both vertically and horizontally.

Based on the method recommended by Demers and Leroueil (2002), continuous profiles of preconsolidation pressure $\left(\sigma_{\mathrm{p}}\right)$ ) were derived from CPTu data using the following equation: $\sigma_{\mathrm{p}}^{\prime}=\left(q_{\mathrm{t}}-\sigma_{\mathrm{v} 0}\right) / N_{\sigma \mathrm{t}}\left(\sigma_{\mathrm{v} 0}\right.$ : in situ total vertical stress, $N_{\sigma \mathrm{t}}$ : cone factor $)$. Two $\sigma_{\mathrm{p}}^{\prime}$ profiles were calculated by using a $N_{\sigma t}$ factor of 3.4, as suggested by Demers and Leroueil (2002), and a site specific $N_{\text {ot }}$ factor. A site specific $N_{\sigma t}$ factor of 4.85 was deduced by relating the $\sigma^{\prime}$ p obtained from the oedometer test on the sample taken at 10.90 $\mathrm{m}$ in core ER-CS09 to the corresponding value of $\left(q_{\mathrm{t}}-\sigma_{\mathrm{v} 0}\right)$ from the CPT09S01 performed $15 \mathrm{~m}$ apart. To correctly relate these two measurements, the in situ depth of the oedometer sample was previously estimated from correlation between $V_{\mathrm{p}}$ measurements on core and in situ at the nearby site Vp13S01 (see Fig.1). Because no significant change in lithology was identified on core ER-CS09, the use of a single $N_{\text {ot }}$ factor is considered reliable for estimating the $\sigma^{\prime}$ p profiles for the superficial sediments, as well as for the underlying deposits of NG1. Vertical effective stress profiles $\left(\sigma^{\prime}{ }_{\mathrm{v} 0}\right)$ were used to deduce profiles of overconsolidation ratio (OCR) as OCR $=\sigma^{\prime}{ }_{\mathrm{p}} / \sigma^{\prime}{ }_{\mathrm{v} 0}$.

From the OCR profile calculated for CPT09S01 with $N_{\sigma \mathrm{t}}=3.4$, the sediments overlying NG1 show magnitude of overconsolidation (Fig. 5a) that is not noticeable within core 
ER-CS09, according to the shear strength profile and its relation to the $S u / \sigma^{\prime}{ }_{v 0}=0.325$ (Fig. 4). Therefore, estimates of OCR using the site specific $N_{\sigma t}$ are considered as more reliable in the study area. According to the OCR profiles thus calculated, the bulk of NG1 deposits are slightly underconsolidated to overconsolidated $(0.8<\mathrm{OCR}<2)$ (Fig. 5). The upper part of NG1 is most commonly overconsolidated (Fig. 5b). However, at 3 sites, simultaneous decreases of more than $40 \%$ of $q_{\mathrm{t}}$ and $\Delta u_{2}$ are observed within the upper 2-3 m of NG1 (Fig. 5a). These local losses of resistance indicate local degree of weakening of the sediments. The most severe weakening is identified on the CPT09S01 profile, where the decrease in tip resistance reaches $80 \%$ over a $3 \mathrm{~m}$ interval (Fig. 5a). It is noteworthy that on the CPTu profiles obtained outside NG1, at a reference site and within the adjacent seabed undulations (Fig. 1c), no weakened zones are identified.

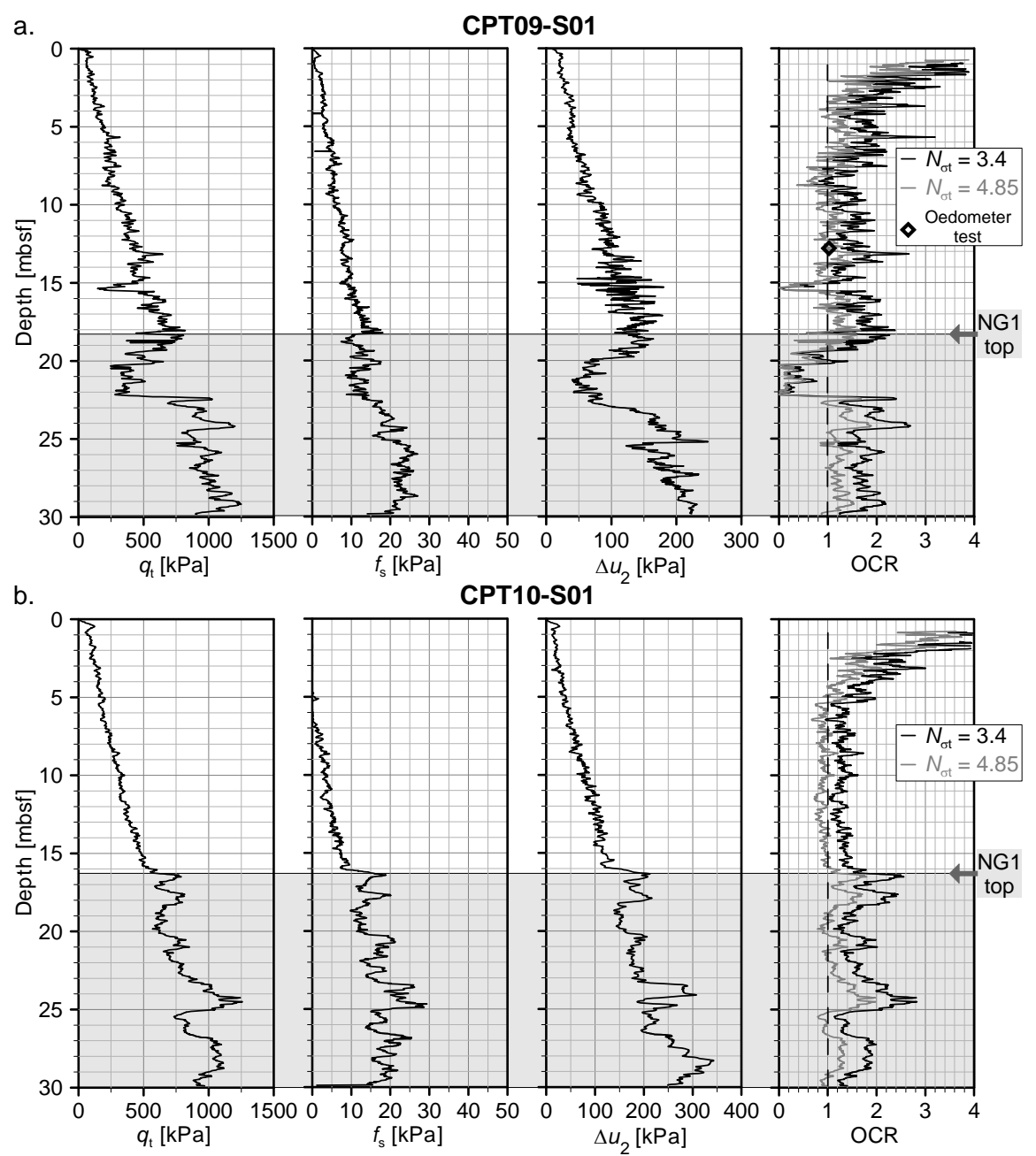

Figure 5. CPTu profiles inside the frontal part of NG1 ( $q_{\mathrm{t}}$ : corrected tip resistance, $f_{\mathrm{s}}$ : sleeve friction, $\Delta u_{2}$ : induced excess pore pressure, OCR: overconsolidation ratio, $N_{\sigma}$ : cone factor). The grey area indicates the location of NG1 body from correlations with seismic data, constrained by detailed time to depth relationship derived from in situ $V_{\mathrm{p}}$ measurements using the sonic fork.

\section{Discussion and Conclusion}

Based on the combined analyses of the seismic, sedimentological and geotechnical data, the internal chaotic structure of the distal part of NG1 reflects complex stress and strain 
partitioning during its emplacement. The high amplitude patches observed in the upper part of NG1 on 2D seismic lines coincide with overconsolidated zones inferred from CPTu data (Figs. 3 \& 5b). Besides, the simultaneous decreases of $q_{\mathrm{t}}, f_{\mathrm{s}}$ and $\Delta u_{2}$ observed at three sites within the upper 2-3 m of NG1 are, according to Demers et al. (1999) and Delisle and Leroueil (2000), the characteristic signature of weakened zones related to the presence of fissures in clay.

These weakened zones show a scattered areal distribution suggesting that they result from local processes rather than being related to a spatially continuous weak layer (Fig. 1). On 2D seismic lines, the weakened zones are located in areas where the top of NG1 is of reduced reflectivity (Fig. 3). On 3D seismic lines, these areas appear as steeply dipping discontinuities along which the top of NG1 is offset (Fig. 2a). Only few of these discontinuities have enough lateral continuity to be detected on the coherency slice as relatively linear features, running parallel to the frontal boundary of NG1 (Fig. 2b). Following Frey-Martinez et al. (2006), these discontinuities are interpreted as highly deformed zones surrounding thrust faults which are consistent with the development of a compressional stress regime through buttressing of the frontal part of NG1 against the MSBH (see Fig. 3). By tying CPTu profiles with both 2D and 3D seismic observations, it is interpreted that weakening is associated with local shearing surrounding syndepositional thrusts faults.

The shear strength along thrust faults likely decreased to the ultimate strength during the emplacement of NG1, but it should have been recovered to some extent following postdepositional consolidation and burial, as suggested by Gibo et al. (2002). Hence, recent changes in boundary conditions emphasising local differences in the stress field in NG1 are required to account for the weakened zones identified. NG1 lies in a complex thinskinned tectonic setting which points towards structural movements as an obvious candidate for inducing changes in boundary conditions. On the upper slope, NG1 is affected by normal growth faults which, according to the escarpment observed on the seabed, appear to have been active relatively recently (Figs. 1 and 6). Moreover, the distal part of NG1 lies above a shale-cored anticline whose relatively recent uplift is manifested by collapse normal faults discernible on the seabed (Figs. 1 and 6). Movements along the growth faults (on the upper slope) and the uplift of the shale-cored anticline (at mid slope) are likely to induce redistribution of the state of stress within NG1. Such a mechanism is suspected to have mobilised syndepositional thrust faults within the frontal part of NG1, resulting in localized plastic shear strains responsible for the identified weakened zones. These last are consequently referred to as shear zones in the following discussion.

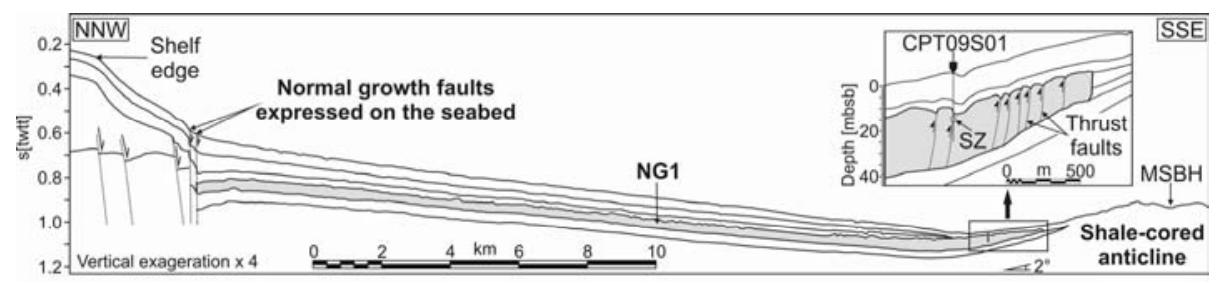

Figure 6. Line drawing depicting the main structural elements bounding NG1 on the upper and midslope regions. (MSBH: mid-slope bathymetric high). Inset shows a close-up of the frontal part of NG1, highlighting the correlation between the shear zone identified on CPT09S01 and the occurrence of a thrust fault. (SZ = shear zone).

Considering the occurrence of shear zones raises concerns about their further propagation, leading potentially to general slope failure (Urciuoli et al., 2007; Puzrin et al., 2004). Without an estimation of the stresses imposed by structural movements, the propagation of the shear zones might be considered under the sole influence of gravity, 
as in the mechanism of catastrophic failure described by Puzrin et al. (2004). These authors showed that the key parameters controlling the catastrophic shear band propagation and bringing the slope to failure are: 1) the depth and length of the discontinuity surface, 2) the residual shear strength along the discontinuity surface, 3) the gravitational shear stress, and 4) the average values of the active and passive lateral pressure. The relatively low residual shear strength within the shear zones in NG1 may favor such catastrophic process (Fig. 5a). However, the low slope angle $\left(<3^{\circ}\right)$ implies low gravitational shear stress. Thereupon, considering that the shear zones are scattered and suspected to result from remobilization of steeply dipping syndepositional thrust faults within NG1, these conditions are likely not favorable for the propagation of a continuous slope-parallel failure surface.

In an attempt to evaluate the impact of structural movements on the potential mobilization of NG1 and on the subsequent activation of the shear zones identified, further studies will use numerical models and integrate the data monitored, over a one year period, by two piezometers and inclinometers deployed in the frontal part of NG1.

\section{Acknowledgements}

We thank the captain, the crew and the technical team aboard the Ifremer R/V Le Pourquoi Pas ? during the ERIG3D cruise. The dedication of the Penfeld and AUV staffs is greatly appreciated. We are indebted to Didier Drapeau from Total who support the ERIG3D project. We finally thank Serge Leroueil and Achim Kopf for their thoughtful review comments.

\section{References}

Delisle M-C, Leroueil S (2000) Détection, à l'aide du piézocône, de zones ramollies dans des pentes argileuses et évaluation de leur comportement mécanique, Report GCT-98-23 prepared for the Ministère des Transports du Québec, Québec: Université Laval.

Demers D, Leroueil S, d’Astous J (1999) Investigation of a landslide in Maskinongé, Québec. Can Geotech J 36: 1001-1014.

Demers D, Leroueil S (2002) Evaluation of preconsolidation pressure and the overconsolidation ratio from piézocône tests of clay deposits in Quebec. Can Geotech J 39: 174-192.

Frey Martinez J, Cartwright J, James D (2006) Frontally confined versus frontally emergent submarine landslides: a 3D seismic characterisation. Mar Pet Geol 23: 585-604.

Gibo S, Egashira K, Ohtsubo M, Nakamura S (2002) Strength recovery from residual state in reactivated landslides. Géotechnique 52 (9): 683-686.

Hooper R J, Fitzsimmons R J, Grant N, Vendeville B C (2002) The role of deformation in controlling depositional patterns in the south-central Niger Delta, West Africa, J Struct Geol, 24(4): 847-859.

Koumoto T, and Houlsby G T (2001) Theory and practice of the fall cone test. Géotechnique 51 (8): 701-712.

Le Gall Y, Pacault A, Mosca A, Greninguey G, Vial M, Aissa J C (2008) Ultra-deep low-frequency sub-bottom profiler for AUV and ROV, Acoustics'08, Paris, France.

Leroueil S (2001) Natural slopes and cuts movement and failure mechanisms. Géotechnique 51(3): 195-243.

Puzrin A M, Germanovich L N, Kim S (2004). Catastrophic failure of submerged slopes in normally consolidated sediments. Géotechnique 54(10):631-643

Sultan N, Voisset M, Marsset B, Marsset T, Cauquil E, Colliat J-L (2007) Potential role of compressional structures in generating submarine slope failures in the Niger Delta, Mar Geol, 237(3-4): 169190.

Sultan N, Cattaneo A, Urgeles R, Lee H, Locat J, Trincardi F, Berne S, Canals M, Lafuerza S (2008) A geomechanical approach for the genesis of sediment undulations on the Adriatic shelf, Geochem. Geophys. Geosyst, 9: 1-15.

Urciuoli G, Picarelli L, Leroueil S (2007) Local soil failure before general slope failure. Geotech Geol Eng 25: 103-122. 